\title{
The experience of anesthesia during kidney transplantation with robot assisted laparoscopic surgery
}

\author{
Yasemin Tekdöş Şeker, Nalan Saygı Emir, Oya Hergünsel, Evrim Tülübaş, Figen Öztürk, Derya \\ Mandacı
}

Department of Anesthesia and Reanimation, University of Health Sciences, Bakırköy Dr. Sadi KonukTraining and Research Hospital, Istanbul, Turkey

DOI: $10.18621 /$ eurj.356547

\begin{abstract}
Objective: Renal transplantation is the most commonly used method to improve the quality of life of patients with end-stage renal failure. Kidney transplantation began in our hospital in 2016 with robot-assisted laparoscopic surgery (RALS). Here, we retrospectively compared the RALS technique and open surgery with respect to anesthesia management during kidney transplant operations done in our clinic.

Methods: Anesthesia management, the duration of the operation and of vascular anastomosis, the amount of fluid delivered perioperatively, amount of urine, and diuretic requirements were investigated retrospectively in cases of renal transplantation (Group O, open surgical technique, $n=22$; Group R, RALS technique, $n=$ 14). Blood gas values, and lactate, bicarbonate, glucose, and electrolyte levels, were examined preoperatively after extubation.

Results: The durations of surgery and vascular anastomosis were significantly longer in Group R than in Group $\mathrm{O}(p<0.05)$. Perioperative liquid volume was not significantly different between Groups $\mathrm{R}$ and A. Postoperative systolic arterial pressure was significantly higher in Group $\mathrm{R}$ than in Group O. As venous blood samples were obtained in Group $\mathrm{O}$ and arterial blood samples were obtained in Group R, blood gas parameters were evaluated within, but not between, groups. The $\mathrm{pH}$ and $\mathrm{HCO}_{3}$ values at the end of the operation were significantly lower, while the lactate level was significantly higher, in Group O compared to Group $\mathrm{R}(p<0.001)$. There was a significant decrease in calcium level at the end of the operation versus pre-anesthesia induction in Group $\mathrm{O}$, but no significant increase in the glucose level was found. There were no significant differences in sodium or potassium levels within or between the groups $(p>0.05)$.

Conclusions: The surgical superiority of RALS technique is known. However, anesthesia management in this patient group is difficult due to the risk of the Trendelenburg position and pneumoperitoneum
\end{abstract}

Keywords: robotic surgical procedures, kidney transplantation anesthesia, pneumoperitoneum, head-down tilt

Received: November 20, 2017; Accepted: February 4, 2018 ; Published Online: February 28,2018

O hronic kidney disease (CKD) is defined as kidney damage in which the glomerular filtration rate (GFR) is $<60 \mathrm{~mL} / \mathrm{min}$ for $\geq 3$ months. A GFR of $<15 \mathrm{~mL} / \mathrm{min}$ is defined as end-stage renal disease
(ESRD) [1]. Today's most effective treatment for ESRD is known as renal transplantation in eligible patients. Cadaveric donor kidney transplantation has been implemented with increasing success rates since

Address for correspondence: Yasemin Tekdöş Şeker, MD., University of Health Sciences, Bakırköy Dr. Sadi KonukTraining and Research Hospital, Department of Anesthesia and Reanimation, Istanbul, Turkey 
1945, and live donor kidney transplantation has been increasing since 1954 [2, 3]. Renal transplantation with classic open surgery for many years has been successfully accomplished with laparoscopic and robotic assisted laparoscopic surgery (RALS) methods with the help of developing technology and increasing laparoscopy experience [4]. Laparoscopic donor nephrectomy has significant advantages such as less pain, premature mobilization and reduction in hospital stay $[4,5]$.

The first robot-assisted laparoscopic kidney transplant was performed successfully in 2002, in a 26-year-old man, by Hoznek et al. [6]. Kidney transplantation has been carried out in our hospital since 2011. The first RALS was performed in our hospital in December 2015, and kidney transplantation with the RALS procedure has since entered into our daily practice.

Experience with nephrectomy and renal transplantation is new with RALS, which is becoming widespread with the use of laparoscopic robot assisted addition with advancing technology. Anesthesia management of patients with RALS shows various differences from open surgery [7].

Open surgical management of renal transplantation, laparoscopic and RALS techniques shows some differences. For this reason, evaluation of the characteristics of anesthesia methods applied for open surgery and RALS method is preliminary.

There are many studies related to anesthesia management of RALS and open surgical procedures. However, there are no similar studies evaluating the management of anesthesia in patients undergoing nephrectomy and renal transplantation. Here, we compared the anesthesia management of 22 open renal transplant surgeries and 14 RALS in cases of ESRD.

\section{METHODS}

After obtaining approval from our ethics committee, we performed a retrospective comparison of 22 renal transplantation cases using open surgical techniques (Group O) and 14 robot-assisted laparoscopic surgical cases (Group R) in 2016. Demographic data, total duration of the operation, duration of vascular anastomosis, perioperative fluid volume, perioperative urine output, and diuretic requirements were evaluated. Blood gas values, and lactate, bicarbonate, glucose, sodium, potassium, and calcium levels, were examined before and after induction of anesthesia. Both groups were subject to standard electrocardiography (ECG) and peripheral $\mathrm{O}_{2}$ saturation monitoring. Noninvasive blood pressure monitoring was used at Group $\mathrm{O}$, invasive blood pressure monitoring was used at Group R. In Group $\mathrm{O}$, four vessels were open intravenously with an 18 Gauge $(\mathrm{G})$ silicone cannula (BICAKCILAR B-CAT2 $18 \mathrm{G})$. The cannula at the distal end was always closed for venous blood gas monitoring. Isotonic infusion into the third vessel was started and the other vessels received anti-human thymocyte globulin (ATGFresenius $\mathrm{S}^{\circledR} 20 \mathrm{mgr} / 5 \mathrm{~mL}$; Fresenius Kabi, Richmond Hill, ON, Canada) and remifentanil infusion. Arterial blood pressure was measured noninvasively. In Group $\mathrm{R}$, two vascular accesses were opened with an $18 \mathrm{G}$ cannula. In Group R both arms were closed. In both groups, $1.5 \mathrm{mg}$ Midazolam (Dormicum ${ }^{\circledR}$, Roche, Germany), $50 \mathrm{mcg}$ Fentanyl (Fentanyl $50 \mathrm{mcg} / \mathrm{mL}$ solution $^{\circledR}$, Mercury, Ireland), $1 \mathrm{~g}$ Acetaminophen, and $100 \mathrm{mg}$ tramadol were administered as premedication. Radial artery cannulation was performed with an 18 G cannula (Seldicath, $1.2 \mathrm{~mm}$; Plastimed, Saint-LeuLa-Forêt, France) with local anesthesia. The arm where fistula is found did not use for monitorization. Blood gases were determined before anesthesia induction in both groups.

Subsequently, induction with $0.05 \mathrm{mg} / \mathrm{kg}$ Midazolam, $1 \mathrm{mg} / \mathrm{kg}$ Propofol (Diprivan ${ }^{\circledR} 10 \mathrm{mg} / \mathrm{mL}$, Fresenius Kabi, USA,), $1.5 \mathrm{mcgr} / \mathrm{kg}$ Fentanyl, and 0.5 $\mathrm{mg} / \mathrm{kg}$ Atracurium besylate $\left(\right.$ Tracrium $^{\circledR} 10 \mathrm{mg} / \mathrm{mL}$, GlaxoSmithKline, Australia) was performed, followed after $120 \mathrm{~s}$ by orotracheal intubation. Ventilation was performed with a ventilator (Maquet ${ }^{\mathrm{TM} \odot}$, Germany) in pressure-regulated volume control (PRVC) mode with $\mathrm{FiO}_{2}<40 \%$, respiratory frequency of $14 / \mathrm{min}$, a positive end-expiratory pressure (PEEP) of 5 , and 7 $\mathrm{kg} / \mathrm{mL}$ vidal volume. Group $\mathrm{O}$ were placed in a slightly supine Trendelenburg position, while Group $\mathrm{R}$ had a Trendelenburg position $\sim 45^{\circ}$ deep. Anesthesia was administered with remifentanil hydrochloride (Ultiva ${ }^{\circledR} 5 \mathrm{mg} / 10 \mathrm{~mL}$, Glaxo Smith Kline, Australia) at $0.1-0.5 \mathrm{mcgr} / \mathrm{kg} / \mathrm{min}$ and sevoflurane (Sevoflurane ${ }^{\circledR}$ $250 \mathrm{~mL}$, Baxter, Australia). Infusion of ATG was performed, and $500 \mathrm{mg}$ methylprednisolone was administered. After completion of venous 
anastomoses, all patients were resuscitated by crystalloid-based fluid replacement. Blood gases were determined at the end of the operation after extubation.

\section{Statistical Analysis}

In the statistical assessment and the analysis of the study, SPSS (ver. 22.0; IBM Corp., Armonk, NY, USA) and PAST 3 software (Hammer et al. [8], 2001) programs were used. The conformity of the data with a single variety to the normal distribution was assessed with Shapiro-Wilk and of the data with multiple variables with Mardia (Dornik and Hansen Omnibus), and for the homogeneity of the variety the Levene test was made. In the comparison of the two independent groups with each other based on the quantitative data, the Independent-Sample $t$ test was used together with the results of Bootstrap, and the Mann-Whitney U test with those of Monte Carlo. In order to investigate the interaction of the dependent variables with those of the repetitive quantitative measurements according to the groups, the general linear model-repeated anova test was used with the results of the Bootstrap. In the comparison of the categoric variables together with each other, the Fisher exact was also tested with the results of the exact. The quantitative variables were shown in the tables as mean \pm standard deviation (SD.) and median range (minimum-maximum) and the categoric ones as $\mathrm{n}(\%)$. The variables were investigated as being 95\% correct, and the $p$ value less than 0.05 was taken meaningful statistically.

\section{RESULTS}

Group $\mathrm{O}$ consisted of 22 patients including 14 (63.6\%) men and 8 (36.7\%) women, Group R consisted of 14 patients including 7 (50\%) men and 7 $(50 \%)$ women. The mean age of the 22 patients in Group O was $44.59 \pm 12.32$ years, and that of the 14 patients in Group R was $37.58 \pm 10.2$ years. There were no statistically significant differences between the two groups for age $(p=0.085)$ and gender $(p=$ 0.418) (Table 1).

The mean duration of operation was $351.82 \pm$ $67.52 \mathrm{~min}$ in Group $\mathrm{O}$ and $412.86 \pm 88.85 \mathrm{~min}$ in Group R (Table 2). The difference in the mean duration of operation between the two groups was statistically significant $(p=0.048)$. The mean duration of vascular anastomosis was significantly longer in Group R than in Group O (34 min vs. 25 min, respectively; $p=0.004$ ) (Table 2 ).

Group O received total 4500 cc fluid and Group $\mathrm{R}$ received total $2700 \mathrm{cc}$ fluid during the perioperative period. The difference between the total fluid volumes of the groups was significant and the volume of fluid given during the operation period of Group $\mathrm{R}$ was found to be very low $(p<0.001)$. The total liquid usage of the groups is shown in Table 2.

Duration time of operations and anastomosis, total fluid, diuretic requirement of the groups are shown in Table 2. There were not found statistically significant difference about need to use perioperative diuretics

Table 1. Demographic data for groups.

\begin{tabular}{lccc}
\hline & Group A $(\mathbf{n}=\mathbf{2 2})$ & Group R $(\mathbf{n}=\mathbf{1 4})$ & $\boldsymbol{p}$ value \\
\hline Age (year) & $44.59 \pm 12.32$ & $37.58 \pm 10.20$ & 0.085 \\
Gender & & & 0.418 \\
Female & $8(36 \%)$ & $7(50 \%)$ & \\
Male & $14(64 \%)$ & $7(50 \%)$ & \\
\hline
\end{tabular}

Data are shown as mean \pm standard deviation or $\mathrm{n}(\%)$ or median.

Table 2. Operation time of groups, duration of anastomosis, fluid management.

\begin{tabular}{lccc}
\hline & Group A $(\mathbf{n}=\mathbf{2 2})$ & Group R $(\mathbf{n}=\mathbf{1 4})$ & $\boldsymbol{p}$ value \\
\hline Operation time (min) & $351.82 \pm 67.52$ & $412.86 \pm 88.85$ & $\mathbf{0 . 0 4 8}$ \\
Vascular anastomosis time (min) & $5(53-13)$ & $34(50-21)$ & $\mathbf{0 . 0 0 4}$ \\
Total fluid replacement $(\mathbf{m l})$ & $4500(10000-2600)$ & $2700(3800-1650)$ & $<\mathbf{0 . 0 0 1}$ \\
Urine output (ml) & $300(3300-0)$ & $250(1300-0)$ & 0.067 \\
Diuretic requirement & & & \\
$\quad$ No & $18(81.8 \%)$ & $12(85.7 \%)$ & 1.000 \\
Yes & $4(18.2 \%)$ & $2(14.3 \%)$ & \\
\hline
\end{tabular}

Data are shown as mean \pm standard deviation or $n(\%)$ or median (minimum-maximum). 
and urine output in the both groups $(p=1.000$ and $p=$ 0.067 , respectively) (Table 2 ).

The difference between pre-induction and postoperative blood gas $\mathrm{pH}$ values of Group $\mathrm{O}$ patients was statistically significant. $(p=0.01)$ (Table 3$)$. In Group $\mathrm{R}$, however, the $\mathrm{pH}$ showed a significant decrease at the end of the operation (pre-induction $\mathrm{pH}$ $=7.41 \pm 0.09$, postoperative $\mathrm{pH}=7.31 \pm 0.05 ; p=$ 0.004 ) (Table 3).
The $\mathrm{PCO}_{2}$ and $\mathrm{PO}_{2}$ values of both groups are shown in Tables 3 and 4. In Group O, there was no significant difference between the preinduction and postoperative $\mathrm{PCO}_{2}(38.67 \pm 5.479 \mathrm{mmHg}$ and 41.19 $\pm 6.06 \mathrm{mmHg}$, respectively; $p=0.053$ ), while $\mathrm{PO}_{2}$ decreased significantly from a preinduction value of $106 \pm 0.5 \mathrm{mmHg}$ to a postoperative value of $85.95 \pm$ $45.57 \mathrm{mmHg}(p=0.03)$ (Table 3). Group R showed no significant changes in $\mathrm{PCO}_{2}(p>0.05)$ or $\mathrm{PO}_{2}(p>$

Table 3. Blood gases, lactate, sodium, calcium, red blood cells, hemodynamic parametres

\begin{tabular}{|c|c|c|c|c|}
\hline & Time & Group O $(n=22)$ & Group R $(n=14)$ & $\boldsymbol{p}^{l}$ \\
\hline & 1 & $1.05 \pm 0.08$ & $1.02 \pm 0.09$ & 0.279 \\
\hline \multirow[t]{2}{*}{ Calcium } & 3 & $0.96 \pm 0.09$ & $1.01 \pm 0.09$ & 0.091 \\
\hline & $(1-3)$ & $0.09 \pm 0.09$ & $0.01 \pm 0.10$ & 0.010 \\
\hline \multirow[t]{2}{*}{$p^{2}$} & & 0.003 & 0.785 & \\
\hline & 1 & $10.61 \pm 1.33$ & $10.25 \pm 2.03$ & 0.519 \\
\hline \multirow[t]{2}{*}{ Hemoglobin } & 3 & $9.61 \pm 1.75$ & $9.59 \pm 1.82$ & 0.970 \\
\hline & $(1-3)$ & $1.00 \pm 1.29$ & $0.66 \pm 1.25$ & 0.447 \\
\hline \multirow[t]{2}{*}{$p^{2}$} & & 0.003 & 0.80 & \\
\hline & 1 & $21.84 \pm 3.75$ & $22.81 \pm 2.87$ & 0.415 \\
\hline \multirow[t]{3}{*}{$\mathrm{HCO}_{3}$} & 3 & $17.76 \pm 2.71$ & $19.55 \pm 2.49$ & 0.048 \\
\hline & $(1-3)$ & $\begin{array}{c}4.08 \pm 2.69 \\
\mathbf{0 . 0 0 1}\end{array}$ & $\begin{array}{c}3.26 \pm 3.34 \\
\mathbf{0 . 0 0 2}\end{array}$ & 0.465 \\
\hline & 1 & $31.27 \pm 3.99$ & $30.43 \pm 5.98$ & 0.614 \\
\hline Hematocrit (Hct) \% & 3 & $28.18 \pm 5.16$ & $28.07 \pm 5.36$ & 0.951 \\
\hline \multirow[t]{2}{*}{$p^{2}$} & $(1-3)$ & $\begin{array}{c}3.09 \pm 3.79 \\
\mathbf{0 . 0 0 1}\end{array}$ & $\begin{array}{c}2.36 \pm 3.95 \\
\mathbf{0 . 0 4 6}\end{array}$ & 0.581 \\
\hline & 1 & $135.20 \pm 3.39$ & $135.64 \pm 2.56$ & 0.679 \\
\hline \multirow[t]{3}{*}{ Sodium } & $\begin{array}{l}3 \\
(1-3)\end{array}$ & $\begin{array}{c}136.32 \pm 4.55 \\
-1.12 \pm 3.02\end{array}$ & $\begin{array}{c}136.22 \pm 3.11 \\
-0.58 \pm 2.94\end{array}$ & $\begin{array}{l}0.947 \\
0.589\end{array}$ \\
\hline & & 0.098 & 0.479 & \\
\hline & 1 & $7.36 \pm 0.07$ & $7.41 \pm 0.09$ & 0.128 \\
\hline \multirow[t]{4}{*}{ pH } & 3 & $7.25 \pm 0.06$ & $7.31 \pm 0.05$ & 0.003 \\
\hline & $(1-3)$ & $0.11 \pm 0.07$ & $0.10 \pm 0.11$ & 0.691 \\
\hline & & 0.001 & 0.004 & \\
\hline & 1 & $106.05 \pm 57.98$ & $154.02 \pm 50.29$ & 0.015 \\
\hline \multirow[t]{4}{*}{$\mathrm{PO}_{2}$} & 3 & $85.95 \pm 45.57$ & $146.62 \pm 64.61$ & 0.005 \\
\hline & $(1-3)$ & $20.10 \pm 38.55$ & $7.40 \pm 83.93$ & 0.574 \\
\hline & & $\mathbf{0 . 0 3 0}$ & 0.751 & \\
\hline & 1 & $136.68 \pm 30.04$ & $158.21 \pm 23.99$ & 0.034 \\
\hline \multirow[t]{2}{*}{ Sistolic blood pressure } & 3 & $138.86 \pm 19.81$ & $156.29 \pm 26.60$ & 0.041 \\
\hline & $(1-3)$ & $-2.18 \pm 29.58$ & $1.93 \pm 29.04$ & 0.685 \\
\hline \multirow[t]{2}{*}{$p^{2}$} & & 0.721 & 0.818 & \\
\hline & 1 & $82.73 \pm 17.71$ & $93.21 \pm 15.01$ & 0.076 \\
\hline \multirow[t]{2}{*}{ Diastolic blood pressure } & 3 & $83.73 \pm 15.18$ & $91.14 \pm 10.11$ & 0.106 \\
\hline & $(1-3)$ & $-1.00 \pm 18.16$ & $2.07 \pm 17.63$ & 0.620 \\
\hline \multirow{4}{*}{ Heart Rate } & & 0.800 & 0.672 & \\
\hline & 1 & $84.32 \pm 18.79$ & $87.64 \pm 21.28$ & 0.624 \\
\hline & 3 & $86.82 \pm 14.82$ & $88.07 \pm 21.30$ & 0.842 \\
\hline & $(1-3)$ & $-2.50 \pm 22.32$ & $-0.43 \pm 19.06$ & 0.776 \\
\hline$p^{2}$ & & 0.600 & 0.941 & \\
\hline
\end{tabular}

Data are shown as mean \pm standard deviation. General Linear Model Repeated Anova (Wilks' Lambda). $p^{1}=$ value for comparison between groups, $p^{2}=$ value for intra-group comparisons, 1 = before induction, 3 = after extubation. 
0.05). Preinduction $\mathrm{HCO}_{3}$ in Group $\mathrm{O}$ was $21.84 \pm$ $3.75 \mathrm{mmol} / \mathrm{L}$, which decreased significantly to a postoperative $\mathrm{HCO}_{3}$ value of $17.76 \pm 2.71 \mathrm{mmol} / \mathrm{L}$ ( $p$ $=0.001)$. In Group R, there was a significant decrease in $\mathrm{HCO}_{3}$ from a preinduction value of $22.81 \pm 2.87$ $\mathrm{mmol} / \mathrm{L}$ to a postoperative value of $19.55 \pm 2.49$ $\mathrm{mmol} / \mathrm{L}(p=0.002)$. There were no statistically significant differences between the two groups at either time point ( $p=0.465)$ (Table 3 ).

Lactate levels increased significantly after the operation in both Group $\mathrm{O}$ (preinduction: $0.9 \mathrm{mmol} / \mathrm{L}$, postoperative value: $1.385 \mathrm{mmol} / \mathrm{L} ; p<0.01)$ and Group R (preinduction: $0.65 \mathrm{mmol} / \mathrm{L}$, postoperative value: $1.385 \mathrm{mmol} / \mathrm{L} ; p=0.001$ ) (Table 4$)$. There was no statistically significant difference between the two groups in terms of changes in perioperative bicarbonate level $(p=0.465)$ (Table 3$)$.

The hemoglobin and hematocrit (Hct) levels of the two groups are shown in Table 3. The Hct levels decreased significantly in both groups after the operation compared to the respective preinduction value (Group O, $31.27 \pm 3.99$ vs. $28.15 \pm 5.16$, respectively; $p=0.001$; Group $\mathrm{R}, 30.43 \pm 5.93$ vs. $28.07 \pm 5.36$, respectively; $p=0.046$ ). There was no statistically significant difference in the postoperative decrease in Hct level between the two groups ( $p=$ $0.581)$. The preinduction and postoperative hemoglobin level decrease in the $\mathrm{O}$ group was statistically significant, but this was not significant in the $\mathrm{R}$ group ( $p=0.003$ and $p=0.080$, respectively). Similarly, there was no statistically significant difference between hemoglobin declines in both groups $(p=0.447)$ (Table 3$)$.

The hemodynamic parameters of the groups are shown in Table 3. The arterial systolic blood pressure in Group R was significantly higher than that in Group $\mathrm{O}(158.21 \pm 23.09 \mathrm{mmHg}$ vs $136.68 \pm 30.04 \mathrm{mmHg}$ respectively; $p=0.034$ ). There was no statistically significant change in mean arterial systolic blood pressure after the operation versus pre-anesthesia induction within either group $(p>0.05)$ (Table 3$)$. There were also no statistically significant differences in arterial diastolic blood pressure or heart rate, either between or within groups.

There were no statistically significant differences in the sodium and potassium levels between groups, either before anesthesia induction or after the operation $(p<0.05)$ (Tables 3 and 4). Preinduction and postoperative decrease of calcium levels were statistically significant in group $\mathrm{O}$ compared to group $\mathrm{R}(p=0.010)$ (Table 3). The mean glucose level in Group $\mathrm{O}$ was $102 \mathrm{~g} / \mathrm{L}$ before induction and $136.5 \mathrm{~g} / \mathrm{L}$ postoperatively $(p<0.001)$, while there was no significant change in Group $R$. There was no statistically significant group difference in the mean electrolyte or glucose level (Tables 3 and 4).

Table 4. Blood gas parameters

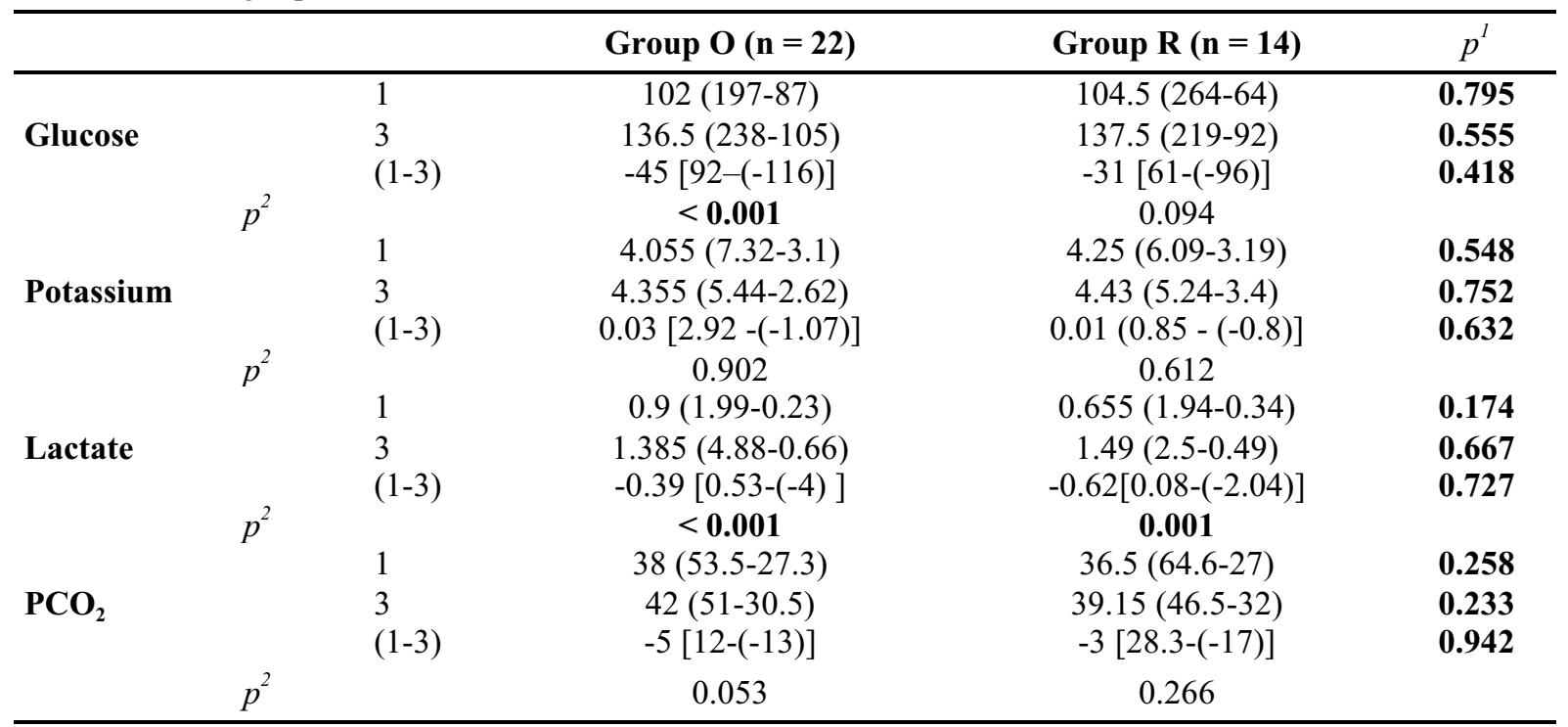

Data are shown as median (minimum-maximum). Mann-Whitney U test (Monte Carlo), Wilcoxon signed ranks test (Monte Carlo). $p^{l}=$ value for comparison between groups, $p^{2}=$ value for intra-group comparisons, $1=$ before induction, $3=$ after extubation. 


\section{DISCUSSION}

RALS with the Da Vinci Surgical System (Intuitive Surgical ${ }^{\circledR}$, Sunnyvale, CA, USA), which uses advanced technology and provides a $3 \mathrm{D}$ view, has improved with increasing surgical experience. In RALS, $\mathrm{CO}_{2}$ pneumoperitoneum is used in the steep Trendelenburg position to remove abdominal viscera from the surgical site $[9,10]$. As the increase in intraabdominal pressure continues in the steep Trendelenburg position, the left ventricle effects a decrease in diastolic end-volume and cardiac output, resulting in tachycardia and hypotension [11]. The effects of the supine position during open surgery on pulmonary and cardiovascular system perfusion are less marked than those of the trendelenburg position [12]. Meininger et al. [9] reported that, for prostatectomy with RALS, pneumoperitoneum and use of the steep Trendelenburg position resulted in increases in all hemodynamic parameters except heart rate and cardiac index, but these parameters returned to baseline values at the end of pneumoperitoneum. Heart rate and cardiac index increased when the patient was placed in the supine position. Pneumoperitoneum results in an increase in systemic vascular resistance, mean arterial pressure, heart rate, and catecholamine release. Kalmar et al. [10] and Pandey et al. [13] reported that mean arterial pressure increased in the steep trendelenburg position and with pneumoperitoneum, respectively.

In the present study, hemodynamic parameters before anesthesia induction remained at normal levels during open surgery, while high systolic arterial pressure was observed pre- and after induction of anesthesia in patients undergoing the RALS procedure. This was taken as a clinical indicator of CKD. While systolic arterial pressure was high in the RALS group, diastolic arterial pressure and heart rate values were both similar to those of the open surgery group. Unlike the studies of Kalmar et al. [10] and Pandey et al. [13], the expected peaks in mean arterial pressure and heart rate while in the steep Trendelenburg position were not observed in our cases. Hemodynamic parameters in both groups returned to baseline values at the end of the operation, and position during surgery showed no effect on hemodynamic parameters.

In our study, the initial hemoglobin levels of both groups were around $10 \mathrm{~g} / \mathrm{dL}$, and did not decrease significantly at the end of the operation. Horgan et al. [14] reported that bleeding control in RALS was as reliable as in open surgery. In the present study, the hemoglobin and hematocrit levels did not change significantly in either group, pre-versus postoperatively. While RALS technique is considered better for a hemostasis control without any anaemia, there is also no such anaemia in the open surgical one of our study. In this regard, our findings were consistent with those in the literature [15-17]. Functional residual capacity (FRC), vital capacity (FVC), peak airway pressure and ventilation/perfusion $(\mathrm{V} / \mathrm{Q})$ mismatch increase when the compliance is reduced in the deep Trendelenburg position in RALS With the diaphragm elevation, the small airline closes. In pneumoperitoneum, decreased compliance, increased V/Q mismatch is observed. In RALS technique, both the deep Trendelenburg position and $\mathrm{CO}_{2}$ insufficiency cause hypercarbia, $\mathrm{pH}$ decrease [10, $12,13,15]$. In our study, hypoxemia was not detected with significant increase in $\mathrm{PCO}_{2}$ values at the end of operation of the groups. The RALS group was protected from mechanical ventilation (MV) maneuvers and the effects of position and pneumoperitoneum on the respiratory system. In our study, changes in $\mathrm{pH}$ and bicarbonate values independent of each other in both groups were thought to be due to chronic renal failure. Low $\mathrm{pH}$ and bicarbonate values are expected in CKD [18-21]. Blood gas monitorizations of patients showed an increase in lactate levels at the end of operation compared to baseline values in both groups. In the presence of hypoxia, tissue hypoperfusion and anaerobic glycolysis lead to elevated lactate levels [21]. There was no statistically significant difference between groups in terms of lactate levels. It was observed that the position used in the surgical technique was not effective at lactic acid levels. Studies of Kalmar et al. [10] and Pandey et al. [13] found high lactate levels in the cases. The hyperlactatemia observed in the study in both groups is consistent with the literature. Liquid restriction in the perioperative period helps to reduce the airway edema during the deep Trendelenburg position. In general, 2 liter fluid is recommended for the prostatectomy operations performed by the RALS technique $[16,17]$. In our study, an average of 2700 
cc crystalloid replacement was performed peroperatively in the RALS group. With this application, it was aimed to provide partial protection from position-dependent fluid overload in the events [22]. In the experience gained from RALS prostatectomy operations, which we have been doing for a long time, liquid restriction in the RALS kidney transplant group in liquid management was deemed appropriate. The need for fluid in RALS is less with open surgery. In our study, less fluid was used for the RALS group than for the open surgery group; The applied liquid management complies with the literature $[7,13,23]$. The most commonly used infusion fluid during kidney transplantation $(0.9 \%)$ is $\mathrm{NaCl}$ [11]. In our study, $0.9 \% \mathrm{NaCl}$ was used for fluid treatment. In our study, diuretic and urine removal were not targeted. For this reason, diuretic use is not discussed.

Horgan et al. [14] reported a mean surgical duration of 166 minutes, Giacomonni et al. [5] reported a mean follow-up of 311 minutes and, in the first case of RALS kidney transplantation reported by Hoznek et al. [6], the operation time was 178 minutes $[8,10,21]$. In our study, RALS group's operation time average is 412 minutes. In line with the longer duration of donor operations, in this study the operation times for the RALS group exceeded those reported in the literature. While the mean duration of vascular anastomosis was 57 minutes in the report by Hoznek et al. [6]. Horgan et al. [14] did not provide information on the operation time. The mean duration of vascular anastomosis in our study was 34 minutes, which was shorter than that reported by Hoznek et al. [6]. Modi et al. [4] have subsequently demonstrated effectiveness of laparoscopic kidney transplantation when the kidney was procured by retroperitoneoscopic living donor nephrectomy. The anastomosis time was longer in the laparoscopic group compared to the open surgery group. We have received a laparoscopic kidney transplantation when the kidney was procured by retroperitoneoscopic living donor nephrectomy. The anastomosis time was longer in the laparoscopic group compared to the open surgery Group O. In the review of all robotic kidney transplantations done in Europe over a 1-year period revealed an average vascular anastomosis operation time of 42 minutes [24]. The mean duration of vascular anastomosis in the RALS group in the present study was those reported in the literature, by an average of 34 minutes. Only 3 of 36 patients included in our study had peritoneal potassium levels $>5.5 \mathrm{mEq} / \mathrm{L}$, and increased potassium levels returned to normal on intravenous glucose-insulin administration. Sodium and potassium levels remained within their respective normal limits at the end of the operation. Calcium levels were lower than expected in the open surgery group during the postoperative period. No information was found in the English language literature on electrolyte levels in RALS.

\section{CONCLUSION}

RALS is being used with increasing frequency due to its minimally invasive nature, reduced surgical stress response, and rapid postoperative recovery. In kidney transplantation operations, the risk of infection due to lymphocele, which is observed frequently with the open surgical technique, is less common in RALS, which is also associated with a shorter hospital stay. However, pneumoperitoneum and use of the steep Trendelenburg position can lead to hemodynamic and respiratory changes, which may result in serious complications. Concomitant comorbidities, such as renal dysfunction, limited systemic reserves, and electrolyte imbalance increase the risk of mortality and morbidity. In this report, we shared our experience of using kidney transplantation with RALS in daily practice.

\section{Conflict of interest}

The authors disclosed no conflict of interest during the preparation or publication of this manuscript.

\section{Financing}

The authors disclosed that they did not receive any grant during conduction or writing of this study.

\section{REFERENCES}

[1] Parmar MS. Chronic renal disease. BMJ 2012;325:85-90.

[2] Margreiter R. Renal Medicine: History of Renal Transplantation [Online]. Available: http://www.renalmed.co.uk/history-of/renaltransplant.

[3] Erek E, Suleymanlar G, Serdengecti K. Nephrology, dialysis and transplantation in Turkey. Nephrol Dial Transplant 2002;17:2087-93. 
[4] Modi P, Rizvi J, Pal B, Bharadwaj R, Trivedi P, Trivedi A, et al. Laparoscopic kidney transplantation: an initial experience. Am J Transplant 2011;11:1320-4.

[5] Giacomoni A, Di Sandro S, Lauterio A, Concone G, Buscemi V, Rossetti $\mathrm{O}$, et al. Robotic nephrectomy for living donation: surgical technique and literature systematic review. Am J Surg 2016;211:113542.

[6] Hoznek A, Zaki SK, Samadi DB, Salomon L, Lobontiu A, Lang P, et al. Robotic assisted kidney transplantation: an initial experience. J Urol 2002;167:1604-6.

[7] Herling SF, Dreijer B, Wrist Lam G, Thomsen T, Moller AM. Total intravenous anaesthesia versus inhalational anaesthesia for adults undergoing transabdominal robotic assisted laparoscopic surgery. Cochrane Database Syst. Rev 2017;4:CD011387.

[8] Hammer Ø, Harper DAT, Ryan PD. PAST: Paleontological Statistics Software Package for Education and Data Analysis. Palaeontol Electron 2001;4:1-9.

[9] Meininger D, Westphal K, Bremerich DH, Runkel H, Probst M, Zwissler B, et al. Effects of posture and prolonged pneumoperitoneum on hemodynamic parameters during laparoscopy. World J Surg 2008;32:1400-5.

[10] Kalmar AF, Foubert L, Hendrickx JFA, Mottrie A, Absalom A, Mortier EP, et al. Influence of steep Trendelenburg position and $\mathrm{CO}(2)$ pneumoperitoneum on cardiovascular, cerebrovascular, and respiratory homeostasis during robotic prostatectomy. Br J Anaesth 2010;104:4339.

[11] Rosendal C, Markin S, Hien MD, Motsch J, Roggenbach J. Cardiac and hemodynamic consequences during capnoperitoneum and steep Trendelenburg positioning: lessons learned from robot-assisted laparoscopic prostatectomy. J Clin Anesth 2014;26:383-9.

[12] O'Brien TJ, Ebert TJ. Physiologic changes associated with the supine position. In Martin JT, Warner MA (ed.): Positioning in Anesthesia and Surgery, 3rd ed. Philadelphia: WB Saunders. 1997.

[13] Pandey R, Garg R, Roy K, Darlong V, Punj J, Kumar A. Perianesthetic management of the first robotic partial cystectomy in bladder pheochromocytoma. A case report. Minerva Anestesiol 2010;76;294-7.

[14] Horgan S, Vanuno D, Sileri P, Cicalese L, Benedetti E. Roboticassisted laparoscopic donor nephrectomy for kidney transplantation. Transplantation 2002;73:1474-9.

[15] Fracalanza S, Ficarra V, Cavalleri S, Galfano A, Novara G, Mangano A, et al. Is robotically assisted laparoscopic radical prostatectomy less invasive than retropubic radical prostatectomy? Results from a prospective, unrandomized, comparative study. BJU Int 2008;101:1145-9.

[16] Phong SVN, Koh LKD. Anaesthesia for robotic-assisted radical prostatectomy: considerations for laparoscopy in the Trendelenburg position. Anaesth Intensive Care 2007;35:281-5.

[17] Danic MJ, Chow M, Alexander G, Bhandari A, Menon M, Brown M. Anesthesia considerations for robotic-assisted laparoscopic prostatectomy: a review of 1,500 cases. J Robot Surg 2007;1:119-23.

[18] Rebholz CM, Coresh J, Grams ME, Steffen LM, Anderson CAM, Appel LJ, et al. Dietary acid load and incident chronic kidney disease: Results from the ARIC Study. Am J Nephrol 2015;42:427-35.

[19] Murray CJL, Richards MA, Newton JN, Fenton KA, Anderson HR, Atkinson C, et al. UK health performance: findings of the Global Burden of Disease Study 2010. Lancet 2013;381:997-1020.

[20] Lentine KL, Kasiske BL, Levey AS, Adams PL, Alberú J, Bakr MA, et al. KDIGO Clinical Practice Guideline on the Evaluation and Care of Living Kidney Donors. Transplantation 2017;101(8 Suppl 1);S7-S105. [21] Streja E, Nicholas SB, Norris KC. Controversies in timing of dialysis initiation and the role of race and demographics. Semin Dial 2013;26:658-66.

[22] Hsu RL, Kaye AD, Urman RD. Anesthetic challenges in roboticassisted urologic surgery. Rev Urol 2013;15:178-84.

[23] Lee JR. Anesthetic considerations for robotic surgery. Korean J Anesthesiol 2014;66:3-11.

[24] Breda A, Territo A, Gausa L, Decaestecker K, Stöckle M, Fornara $\mathrm{P}$, et al. Robotic kidney transplantation: European one-year data. Eur Urol 2018;16 Suppl;e1977-8. 